\title{
Performance of stroke risk scores in older people with atrial fibrillation not taking warfarin: comparative cohort study from BAFTA trial
}

\author{
F D R Hobbs professor and head of department ${ }^{1}$, A K Roalfe senior lecturer in medical statistics ${ }^{2}$, \\ G Y H Lip consultant cardiologist ${ }^{3}$, K Fletcher research fellow ${ }^{2}$, D A Fitzmaurice professor of primary \\ care $^{2}$, J Mant professor of cardiovascular research ${ }^{4}$
}

${ }^{1}$ Department of Primary Care Health Sciences, University of Oxford, Oxford OX1 2ET, United Kingdom; ${ }^{2}$ Primary Care Clinical Sciences, Primary Care Clinical Sciences Building, University of Birmingham, Birmingham B15 2TT; ${ }^{3}$ University of Birmingham Centre for Cardiovascular Sciences, City Hospital, Birmingham B18 7QH; ${ }^{4}$ Department of General Practice, University of Cambridge, Cambridge

\begin{abstract}
Objective To compare the predictive power of the main existing and recently proposed schemes for stratification of risk of stroke in older patients with atrial fibrillation.

Design Comparative cohort study of eight risk stratification scores.

Setting Trial of thromboprophylaxis in stroke, the Birmingham Atrial Fibrillation in the Aged (BAFTA) trial.

Participants 665 patients aged 75 or over with atrial fibrillation based in the community who were randomised to the BAFTA trial and were not taking warfarin throughout or for part of the study period.

Main outcome measures Events rates of stroke and thromboembolism.

Results $54(8 \%)$ patients had an ischaemic stroke, four $(0.6 \%)$ had a systemic embolism, and $13(2 \%)$ had a transient ischaemic attack. The distribution of patients classified into the three risk categories (low, moderate, high) was similar across three of the risk stratification scores (revised $\mathrm{CHADS}_{2}$, NICE, ACC/AHA/ESC), with most patients categorised as high risk (65-69\%, $\mathrm{n}=460-457)$ and the remaining classified as moderate risk. The original $\mathrm{CHADS}_{2}$ (Congestive heart failure,

Hypertension, Age $\geq 75$ years, Diabetes, previous Stroke) score identified the lowest number as high risk $(27 \%, \mathrm{n}=180)$. The incremental risk scores of $\mathrm{CHADS}_{2}$, Rietbrock modified $\mathrm{CHADS}_{2}$, and $\mathrm{CHA}_{2} \mathrm{DS}_{2}-\mathrm{VASC}$

( $\mathrm{CHA}_{2} \mathrm{DS}_{2}$-Vascular disease, Age 65-74 years, Sex) failed to show an increase in risk at the upper range of scores. The predictive accuracy was similar across the tested schemes with $\mathrm{C}$ statistic ranging from 0.55 (original $\mathrm{CHADS}_{2}$ ) to 0.62 (Rietbrock modified $\mathrm{CHADS}_{2}$ ), with all except the original $\mathrm{CHADS}_{2}$ predicting better than chance. Bootstrapped paired comparisons provided no evidence of significant differences between the discriminatory ability of the schemes.
\end{abstract}

Conclusions Based on this single trial population, current risk stratification schemes in older people with atrial fibrillation have only limited ability to predict the risk of stroke. Given the systematic undertreatment of older people with anticoagulation, and the relative safety of warfarin versus aspirin in those aged over 70 , there could be a pragmatic rationale for classifying all patients over 75 as "high risk" until better tools are available.

\section{Introduction}

Atrial fibrillation is the most common chronic cardiac arrhythmia and is associated with increased morbidity and mortality. ${ }^{1}$ Recent data from the Screening for Atrial Fibrillation in the Elderly (SAFE) trial showed a prevalence of atrial fibrillation of $6 \%$ in people aged $65-74,12 \%$ in people aged $75-84$, and $16 \%$ in people aged 85 and over. ${ }^{2}$ The main importance of atrial fibrillation is that it remains a major independent risk factor for stroke and thromboembolism, particularly in older patients.

A large evidence base supports the efficacy of oral anticoagulation (with vitamin $\mathrm{K}$ antagonists, such as warfarin), which can reduce the risk of stroke by two thirds. ${ }^{4}$ The alternative of antiplatelet treatment decreases the risk of stroke by only $22 \%,{ }^{5}$ a reduction that might merely reflect the known benefits of aspirin in secondary prevention of cardiovascular disease. Despite this better efficacy, however, vitamin K antagonists have been perceived as linked to more adverse events in older people ${ }^{6}$ and are costlier and more complicated to implement because of the need to monitor the international normalised ratio (INR), leading to guidelines recommending the use of stroke risk scores to triage patients to vitamin $\mathrm{K}$ antagonists or aspirin. Even though a new generation of anticoagulants (oral direct thrombin inhibitors and oral factor Xa inhibitors), which do not require monitoring, are starting to 
gain market authorisation, their initial high cost will mean they will not entirely displace vitamin $\mathrm{K}$ antagonists or, therefore, remove the need to stratify risk in patients, especially as the new agents have similar risks of bleeds to vitamin $\mathrm{K}$ antagonists.

Various clinical and investigation features have been incorporated into several risk stratification schemes, usually with categories of high, intermediate/moderate, or low risk, equating to the likely stroke risk by category. For example, application of the $\mathrm{CHADS}_{2}$ (Congestive heart failure, Hypertension, Age $\geq 75$ years, Diabetes, previous Stroke) score in one cohort ${ }^{7}$ resulted in an observed annual risk of stroke of under $2 \%$ for those with a score of 0 (defined as low risk), around $3 \%$ for those with a score of 1 (moderate risk), and over $4 \%$ for those with a score of 2 (moderate risk in the original $\mathrm{CHADS}_{2}$ score, high risk in the revised $\mathrm{CHADS}_{2}$ score), rising to $13 \%$ at score 5 and $18 \%$ at score 6 . These various scores are derived largely from risk factors identified from the non-vitamin $\mathrm{K}$ antagonist arms of trial cohorts and one historical cohort study (Framingham). Unfortunately, these derivation cohorts show considerable diversity in the characteristics of the patients included (table 1) and are therefore not particularly representative of the general population with atrial fibrillation, especially in relation to the low proportion of older patients in the cohorts. Furthermore, the proportion with previous stroke or transient ischaemic attack is highly variable, from a high of $25 \%$ in the cohort first used to test $\mathrm{CHADS}_{2}{ }^{7}$ using a sample from the National Registry of Atrial Fibrillation in the United States, to a low of $3.3 \%$ in the cohort by van Walraven et al. ${ }^{8}$ Not surprisingly therefore, existing stroke risk stratification schemes have widely varying proportions categorised as high, intermediate, and low risk, and previous studies have shown generally modest predictive value in predicting stroke and thromboembolism (C statistics of about 0.6$){ }^{9}$

This poses the question of whether stroke risk scores are adequate, especially in older people, in whom rates of atrial fibrillation are the highest (56\% of the prevalent population in the United Kingdom with atrial fibrillation are aged over 75 and $85 \%$ over $65^{10}$ ) and the risks of stroke are the greatest. Populations of older people have not been systematically studied in previous validation studies of stroke risk scores.

Recent data from the Birmingham Atrial Fibrillation Treatment of the Aged (BAFTA) trial have supported the use of vitamin $\mathrm{K}$ antagonists (to target INR of 2.5) in older people, with a reduction in major disabling stoke of $52 \%$ compared with aspirin $75 \mathrm{mg}$ daily and no difference in major bleeding events. ${ }^{11}$ Indeed, the efficacy of aspirin seems to decline beyond the age of 70 , whereas the risk of bleeding increases. ${ }^{12}$ Even in low risk patients with atrial fibrillation, aspirin might be no better than placebo for reducing thromboembolic events and have more adverse effects (especially bleeding). ${ }^{13}$ Current evidence is therefore more definitive regarding treatment recommendations: all high risk patients should be offered a vitamin $\mathrm{K}$ antagonist, if it can be tolerated, as well as most patients at intermediate risk.

Continued surveys, however, show that less than half of patients eligible for warfarin are treated with a vitamin $\mathrm{K}$ antagonist,

and rates of underuse are highest in older people. ${ }^{14}$ Stroke risk scores might therefore continue to have a practical role as long as therapeutic dilemmas remain, but only if they reliably distinguish between risk groups.

A recent study in the $B M J$ reported the observed annual rates of thromboembolic events in a large registry cohort of Danish patients admitted with atrial fibrillation and compared this to risk categorisation estimated by $\mathrm{CHADS}_{2}$ and $\mathrm{CHA}_{2} \mathrm{DS}_{2}-\mathrm{VASc}$ $\left(\mathrm{CHA}_{2} \mathrm{DS}_{2}\right.$-Vascular disease, Age $65-74$ years, Sex $) .{ }^{15}$ Oleson et al showed that rates were similar for patients classified as low risk but were divergent in patients assessed as moderate risk, with observed annual event rates of 4.7 and 2.0, respectively. They also explored the relative importance of the various risk factors incorporated into the scores and showed that age $>75$ was the dominant risk factor in $\mathrm{CHADS}_{2}$ (and hypertension the least important) and diabetes the most important factor in $\mathrm{CHA}_{2} \mathrm{DS}_{2}-\mathrm{VASc}$. Such registry studies are complemented by data such as in the BAFTA study, which are not subject to the potential ascertainment bias of registries and are controlled for use of drug treatments. Furthermore, these BAFTA data are uniquely focused on the performance of the risk scores in those over 75, not separated in the Oleson paper, ${ }^{15}$ the most important population for stroke prevention in atrial fibrillation.

We tested the predictive power of the main scoring schemes for risk of stroke advocated in international guidelines against the observed rates of stroke and thromboembolic events in people aged over 75 with chronic atrial fibrillation recruited to the BAFTA trial. The relevance of this cohort being patients aged over 75, by far the most common group to have atrial fibrillation, is that they have been under-represented in previous atrial fibrillation trials and, further, the BAFTA study population was representative of older people in the general population with atrial fibrillation because of the limited study exclusions.

\section{Methods}

We compared the performance of the commonly used stroke risk stratification schemes in a contemporary population of older people. Seven schemes were applied to a subset of data from the BAFTA study.

\section{Stroke risk stratification schemes}

The schemes evaluated were $\mathrm{CHADS}_{2},{ }^{16}$ Framingham, ${ }^{17}$ NICE guidelines, ${ }^{18}$ ACC/AHA/ESC (American College of Cardiology/American Heart Association/European Society of Cardiology) guidelines, ${ }^{19} \mathrm{ACCP}$ guidelines, ${ }^{20}$ and the more recently developed $\mathrm{CHA}_{2} \mathrm{DS}_{2}-\mathrm{VASc}^{21}$ and Reitbrock modified $\mathrm{CHADS}_{2}$ scheme. $^{22}$ All but the Reitbrock scheme classify patients into risk categories (low, moderate, high) following stratification rules (table 1). All seven schemes identify older age, previous stroke/transient ischaemic attack, and diabetes as risk factors. All but Reitbrock include hypertension (Framingham includes systolic blood pressure). Heart failure or left ventricular dysfunction is included in all schemes except Framingham and Reitbrock. Other factors considered are sex (Framingham, Reitbrock, $\mathrm{CHA}_{2} \mathrm{DS}_{2}$-VASc), valve disease (NICE and ACC/AHA/ESC (mitral stenosis)), and vascular disease (NICE, $\mathrm{CHA}_{2} \mathrm{DS}_{2}$-VASc).

The $\mathrm{CHADS}_{2}$ index is the simplest to construct, with a score ranging from 0 to 6 ; two points are given for previous stroke/transient ischaemic attack and one point for each of congestive heart failure, hypertension, age 75 and older, and diabetes. A reported weakness of the original $\mathrm{CHADS}_{2}$ score is that a person with previous stroke or transient ischaemic attack and no other risk factors was allocated to the moderate risk category, despite the medical history suggesting high risk. ${ }^{23}$ To address this limitation, the revised $\mathrm{CHADS}_{2}$ index (score $0=$ low risk; $1=$ moderate risk; $2-6$ high risk) was proposed to replace the original $\mathrm{CHADS}_{2}$ (score $0=$ low risk; 1-2=moderate risk; 3-6 high risk). More recently Reitbrock et al further modified $\mathrm{CHADS}_{2}$ into a new scale from 0 to 14 , where the original algorithm was altered by reweighting age, including sex, and removing heart failure and hypertension. ${ }^{22}$ The risk strata cut offs for this scale, however, have not been published so analysis 
of this scheme is performed on the score only. The new $\mathrm{CHA}_{2} \mathrm{DS}_{2}$-VASc score is expressed as a point based scoring system from 0 to 9 , whereby $0=$ low risk, $1=$ intermediate, and $\geq 2$ is high risk. The $\mathrm{CHA}_{2} \mathrm{DS}_{2}-\mathrm{VASc}$ score evolved from the ACC/AHA/ESC and NICE guidelines and initially tested a large cohort of patients from the Euro Heart Survey for atrial fibrillation. International guidelines recommend that all patients assessed as high risk and most patients at moderate risk with these scores are offered warfarin, unless it is contraindicated or not tolerated. Recommendations are more varied for patients at low risk, with some guidelines advocating aspirin and some no medication.

\section{Investigational cohort}

The investigational cohort for this analysis is a subset of participants of the Birmingham Atrial Fibrillation Treatment of the Aged (BAFTA) trial. ${ }^{11}$ In brief, this randomised controlled trial, undertaken in primary care, compared warfarin with aspirin for stroke prevention in older people with atrial fibrillation. The trial recruited 973 patients aged 75 and over from 260 general practices throughout England and Wales from 2001 to 2004. Eligible patients were identified from general practice registers and opportunistic pulse tests during routine general practice visits. Atrial fibrillation was confirmed by a study electrocardiogram or by electrocardiography performed in the previous two years if the study electrocardiogram showed sinus rhythm but there was evidence that the patient had paroxysmal atrial fibrillation. All potential strokes, systemic emboli, and transient ischaemic attacks were independently adjudicated. The study population for these analyses comprised BAFTA patients not taking warfarin for all or part of the trial period $(n=665)$; table 2 shows the demographics. For this analysis, participants contributed person years at risk only for the time they were not taking warfarin. Sensitivity analyses were performed on a subset of patients identified as taking aspirin throughout the trial $(n=368)$.

\section{Statistical methods}

Our primary analysis focused on the predictive accuracy of the different tools in classifying the risk of ischaemic stroke. Secondary analyses examined the tools' performance for prediction of ischaemic stroke, systemic embolism, or transient ischaemic attack. Event rates (per 100 person years) were calculated for each risk scheme and stratum, with $95 \%$ confidence intervals estimated with the Poisson exact method. To assess the validity of the schemes, we used Cox proportion hazards regression analysis on the time to event data. Hazard ratios were obtained to measure the increased risk of stroke across the risk strata. The $\mathrm{C}$ statistic was calculated to quantify the discriminatory ability of each risk scheme, where a value of 0.5 indicates that the tool performs no better than chance. Bootstrapping was undertaken to assess the accuracy of the $\mathrm{C}$ statistic. It enables us to calculate a distribution of the $\mathrm{C}$ statistic from which we can calculate the $95 \%$ confidence interval. If the confidence interval overlaps 0.5 , then the risk tool's predictive ability is no better than chance. The $95 \%$ confidence intervals for each C statistic were estimated from centiles (2.5th, 97.5th) obtained from bootstrap resampling with 1000 replications. These intervals also enable comparisons to be made between risk strata. For comparison across schemes, allowing for correlation between them, we calculated differences between the $\mathrm{C}$ statistics for each paired comparison from every bootstrapped sample. The difference between the schemes was considered significant if the $95 \%$ confidence interval of these bootstrapped differences did not include zero.
The risk tools under consideration have been designed for use in adults. As BAFTA is a study of people aged 75 and over, we carried out an additional time to event analysis to confirm whether those independent risk factors, identified by the various schemes, are confirmed in the new model derived from an older population. Variables considered were age, sex, systolic blood pressure, history of stoke or transient ischaemic attack, valve disease, hypertension, diabetes, myocardial infarction, angina, and heart failure. Trial participants were recruited from many general practices so we examined potential clustering effect using a Cox shared frailty model. ${ }^{24}$ The proportional hazards assumptions were checked with Schoenfeld residuals. ${ }^{25}$ Analyses were performed with SAS version 9.1 and Stata Version 10.

\section{Results}

Of the patients randomised to the BAFTA trial, 665 aged 75 or over with atrial fibrillation were identified as not taking warfarin throughout or for part of the study period. The median follow-up of these patients while they were not taking warfarin was 2.2 years (range 0-5.3 years), the mean age was 81 (SD 4.3), and $55 \%$ (367) were men (table 2). The distribution of patients classified into the three risk categories was similar across the revised $\mathrm{CHADS}_{2}$, NICE, ACC/AHA/ESC, and ACCP, with most patients categorised as high risk (65-69\%, 430-457), and, with the exception of ACCP, the remaining were classified as moderate risk. The original $\mathrm{CHADS}_{2}$ identified the fewest as high risk $(27 \%, 180)$. Only Framingham and ACCP classified some patients as low risk (17\% (112) and 3\% (19), respectively). The $\mathrm{CHA}_{2} \mathrm{DS}_{2}$-VASc score classified all patients (given all were aged $\geq 75$ ) as high risk. Three items required for the calculation of ACC/AHA/ESC - namely, impaired left ventricular function, mitral stenosis, and prosthetic heart valve-were exclusion criteria for the BAFTA trial, hence this scheme produced estimates identical to the revised $\mathrm{CHADS}_{2}$.

During the trial follow-up, 54 patients (8\%) had an ischaemic stroke, four $(0.6 \%)$ had a systemic embolism, and $13(2 \%)$ had a transient ischaemic attack. Table 3 shows the number of observed ischaemic strokes, patient years, and event rates by each risk stratum for the different schemes. The highest rates of stroke were in the high risk category, with rates across all stratification schemes ranging between 4.36 per 100 person years for NICE to 4.98 per 100 person years for the original $\mathrm{CHADS}_{2}$. These high risk event rates were significantly different from the moderate rates for all schemes, except the original $\mathrm{CHADS}_{2}$ and Framingham. A low rate of 0.76 per 100 person years was found for the low risk strata of Framingham and 2.38 per 100 person years for low risk as defined by ACCP. The incremental risk scores of $\mathrm{CHADS}_{2}$, Rietbrock, and

$\mathrm{CHA}_{2} \mathrm{DS}_{2}-\mathrm{VASc}$ failed to show an increase in risk at the upper range of scores (table 4). The figure shows the similarity of risk rates of $\mathrm{CHADS}_{2}$ scores 2 and above.

Table 5 shows the performance characteristics of the different stratification schemes. With the exception of Framingham and the original $\mathrm{CHADS}_{2}$, schemes that enabled categorisation of patients into risk strata showed about a threefold increase in risk of stroke when patients move between moderate and high categories of risk. The revised $\mathrm{CHADS}_{2}$ had the highest hazard ratio, with a significant increase in risk from moderate to high of 3.29 (95\% confidence interval 1.49 to 7.28). The $\mathrm{CHADS}_{2}$ index, Rietbrock modified, and $\mathrm{CHA}_{2} \mathrm{DS}_{2}$-VASc scoring schemes estimating a $17-35 \%$ increase in risk per unit change in score. The predictive accuracy was similar across the seven schemes, with the $\mathrm{C}$ statistic ranging from 0.55 (original $\mathrm{CHADS}_{2}$ ) to 0.62 (Rietbrock modified $\mathrm{CHADS}_{2}$ ), with all except 
the original $\mathrm{CHADS}_{2}$ predicting better than chance. Bootstrapped paired comparisons provided no evidence of significant differences between the discriminatory ability of the schemes. Evaluation of the validity of the different classification schemes identifying the additional events of systemic embolism and transient ischaemic attack produced similar results (see tables $\mathrm{B}$ and $\mathrm{D}$ in appendix on bmj.com).

The sensitivity analysis of 368 patients taking aspirin throughout the trial follow-up period, with 34 ischaemic strokes occurring in this population, showed similar risk rates to those observed across the primary population of all non-warfarin users (see tables $\mathrm{A}$ and $\mathrm{C}$ in appendix on bmj.com). The Framingham risk rate of ischaemic stroke in the moderate group (5.03 per 100 person years) was greater in magnitude than in the high risk group (3.63 per 100 person years). Comparison of confidence intervals, however, confirmed no significant difference between these categories. There was a wider range of $\mathrm{C}$ statistics from 0.5 (original $\mathrm{CHADS}_{2}$ ) to 0.62 (Framingham) compared with the prediction of stroke only, but again there was no evidence of any significant differences between the schemes.

Table 6 presents the results of the Cox proportional hazards survival analysis to identify independent risk factors in these older people with atrial fibrillation. As there was no evidence of practices having a clustering effect on the outcome, it was excluded from the further analyses. After adjustment for all other factors in the model, only history of diabetes (hazard ratio $2.06,1.07$ to 3.98 ) and previous stroke or transient ischaemic attack $(2.59,1.36$ to 4.90$)$ were identified as significant risk factors of ischaemic stroke. A rule with these two factors has a moderate ability to predict stroke (C statistic $0.60,0.53$ to 0.68 ).

\section{Discussion}

This comprehensive assessment of current risk stratification schemes in older people with atrial fibrillation, commonly recommended in international guidelines, has shown that all schemes studied have a similar limited ability to predict the risk of stroke. The significance of these results is threefold: the prevalence of atrial fibrillation is highest in older people (approaching 60\% of patients with atrial fibrillation in the UK are over 75), among people with atrial fibrillation, stroke is more common in the older patients, and, when they do occur, strokes tend to be more disabling in older people. Previous studies have systematically under-represented older people, leaving uncertainty about how to weight age within the current risk scores. These data therefore provide original estimates of the utility of existing scores in the most important target population for prevention of stroke in people with atrial fibrillation.

All the schemes evaluated worked similarly, with the highest event rates for stroke occurring in the high risk category. This was also observed in the composite event rates for systemic embolism and transient ischaemic attack. The proportion of patients that are classified as high, moderate, or low risk, however, varies considerably across the schemes. These observed differences are reflected in the general inconsistent use of anticoagulation in the treatment of patients with atrial fibrillation. The simple reclassification of $\mathrm{CHADS}_{2}$, where those with a score of 2 or more are categorised at high risk, resulted in the largest hazard ratio. Its ability to discriminate between the risk groups, with a $\mathrm{C}$ statistic of 0.61 , however, is similar to the other schemes. Previous concern with the original $\mathrm{CHADS}_{2}$ was confirmed by its failure to show a significant increase in risk between the moderate and high risk strata. Its $\mathrm{C}$ statistic is also lowest in magnitude and was found to perform no better than chance in the BAFTA data. The moderate ability of the tools to predict stroke in these older people is therefore similar to the results seen in previous research across wider age groups. ${ }^{96}$

\section{Study limitations}

Patients recruited for the BAFTA trial were those for whom general practitioners were in equipoise over the benefits and risks of treatment. Therefore, those perceived as at highest risk might have been less likely to have been recruited. However, a range of "at risk" older people were randomised, including some living in nursing homes (and requiring carer consent), those previously treated with warfarin, and people with previous stroke. We were unable to assess some of the risk factors in the ACC/AHA/ESC scheme because of the lack of available data. The $\mathrm{C}$ statistics and hazard ratios for the point scoring schemes of $\mathrm{CHADS}_{2}$, Rietbrock, and $\mathrm{CHA}_{2} \mathrm{DS}_{2}$-VASc should be read with caution as the low number of events prevented the linearity assumption for these scales being adequately tested. Also, all participants in BAFTA were classified as "high risk" based on the $\mathrm{CHA}_{2} \mathrm{DS}_{2}$-VASc score (that is, $\geq 2$ ). We cannot account for any unanticipated influence of previous exposure to drug treatment on subsequent embolic events, though sensitivity analysis of those taking aspirin throughout generated similar results.

\section{Clinical relevance}

These data are important as high risk atrial fibrillation patients should be offered vitamin $\mathrm{K}$ antagonists in most circumstances, yet vitamin $\mathrm{K}$ antagonists are underused for stroke prevention. The NICE recommendations for atrial fibrillation treatment estimated that nationally of 355312 patients with atrial fibrillation who should be taking warfarin, 165946 (50\%) were not receiving it. ${ }^{27}$ Audits suggest that warfarin continues to be underused in the UK. ${ }^{28}{ }^{29}$ This pattern of underuse of vitamin K antagonists recurs internationally, with data from the $\mathrm{US}^{30}$ showing only about one third of visits of patients for atrial fibrillation included mentions of vitamin $\mathrm{K}$ antagonists, with no significant change over time, and Spain, where $69 \%$ of 1178 patients with atrial fibrillation were not taking anticoagulants, ${ }^{31}$ despite $89 \%$ patients having strong indications for anticoagulation. Furthermore, data suggest that use of vitamin $\mathrm{K}$ antagonist declines over time, ${ }^{32}$ with one North American study showing a $65 \%$ use of warfarin at diagnosis but only $44 \%$ taking it at 30 months. Even in "ideal" candidates for a vitamin $\mathrm{K}$ antagonist, the rate of its prescription decreased from $70 \%$ at baseline to $50 \%$ at 30 months.

There are recognised difficulties in implementing the guidelines for anticoagulant, ranging from reluctance of patients to adopt current treatment guidelines to difficulties in identifying patients with atrial fibrillation ${ }^{33}$ - diagnosis of atrial fibrillation in older patients can be a particular challenge in that older adults might have no symptoms or might present with such atypical symptoms as a change in function, mood, or cognition. Moreover, physicians' reluctance to use vitamin $\mathrm{K}$ antagonists has repeatedly been shown to be associated with a false understanding of the benefit to risk ratio, which arises from a low appreciation of therapeutic benefits and a high concern regarding haemorrhage. ${ }^{34} \mathrm{~A}$ study in the Netherlands to assess which clinical determinants influence prescription of coumarin and aspirin in patients with atrial fibrillation in primary care found that physicians' decisions about initiating antithrombotic treatment in atrial fibrillation were not evidence based and were guided only partly by thromboembolic risk stratification but also by factors insignificant for thromboembolic risk. ${ }^{35}$ 
Established risk factors for future thromboembolic events, such as hypertension and diabetes mellitus, did not lead to higher prescription rates of coumarin compared with aspirin, but, in contrast, several factors not associated with thromboembolic events, such as chronic (versus paroxysmal) atrial fibrillation (adjusted odds ratio 3.7, 1.7 to 8.2) and longstanding (versus recent) diagnosis $(2.2,1.1$ to 4.5$)$, were associated with higher coumarin prescription.

\section{Importance in older people}

The underprescribing of vitamin $\mathrm{K}$ antagonists in older patients is a particular issue. ${ }^{14}$ Age is itself a recognised risk factor in both the $\mathrm{CHADS}_{2}$ and NICE schemes that should be linked to higher risk scores and therefore increased probability of being prescribed anticoagulants. Vitamin K antagonists, however, are even less likely to be optimally prescribed to this group, probably compounded by many guidelines assessing age as both a risk factor for stroke and a caution for risk of bleeding with anticoagulation. Unsurprisingly therefore, older people are the least likely to be receiving preventive treatment, despite being the most at risk: among patients with atrial fibrillation admitted to hospital in Ireland, those aged 75 and older were more likely to be receiving suboptimal oral antithrombotic treatment compared with younger patients. ${ }^{36}$ In Canada, $46 \%$ of atrial fibrillation patients deemed appropriate candidates for warfarin were not prescribed it, and age was a particularly important factor. Multivariable analysis found that increasing age was associated with a reduced odds of use of a vitamin $\mathrm{K}$ antagonist (odds ratio $0.7,0.5$ to 0.9 ); $75 \%$ of those under 75 considered suitable by the study's authors were prescribed vitamin $\mathrm{K}$ antagonists compared with only $33 \%$ of those over $85 .{ }^{37}$ Of 111 patients with atrial fibrillation in west Birmingham who were not receiving an anticoagulant $(\mathrm{n}=71)$, less than $17 \%$ had contraindications, and patients treated with warfarin were significantly younger than those who were not prescribed it. ${ }^{38}$ A similar pattern has been identified in Iceland, ${ }^{39}$ Sweden, ${ }^{40}$ and the US. ${ }^{41}$

Better prevention of stroke in older patients with atrial fibrillation is therefore a priority. Importantly, the BAFTA trial ${ }^{11}$ and subsequent individual patient data meta-analysis ${ }^{12}$ have shown that the risk of bleeding with warfarin in older patients is no greater than with aspirin. Indeed the meta-analysis shows that whereas the benefits and risks of warfarin remain constant across all age bands, aspirin becomes progressively less effective and the risk of bleeding increases with advancing age, with its effectiveness in preventing stroke seeming to cease beyond the age of $70 .{ }^{12}$ Furthermore, the options for anticoagulation treatment are being expanded beyond warfarin. A new direct thrombin inhibitor, dagibatran, recently gained European approval for marketing in atrial fibrillation thromboprophylaxis, ${ }^{42}$ as did two factor Xa inhibitors: rivaroxaban recently showed equivalence to warfarin in prevention of atrial fibrillation stroke ${ }^{43}$ and apixiban showed a greater than $50 \%$ risk reduction in thromboembolic events compared with aspirin in atrial fibrillation patients who could not tolerate warfarin. ${ }^{44}$ Therefore, even if patients and physicians remain reluctant to prescribe warfarin, accurate identification of those at high thromboembolic risk remains a priority as effective management alternatives to warfarin options, that don't require monitoring, become available. Offering such patients aspirin is an inappropriate option.

None of the stroke risk scores performed particularly well in these older people, with the best performance of the revised $\mathrm{CHADS}_{2}$ and $\mathrm{CHA}_{2} \mathrm{DS}_{2}-\mathrm{VASc}$ managing only a $\mathrm{C}$ statistic around 0.60 . This compares with the $\mathrm{C}$ statistics of $>0.70$ observed for the various commonly used 10 year estimates for cardiovascular disease. Based on these data, a more pragmatic solution to better stroke prevention in atrial fibrillation in older people might be to recommend that all patients over 75 are considered for anticoagulation (as suggested in the 2010 European Society of Cardiology guidelines) without the need for a risk score and to reserve the use of risk scores for those under 75 .

\section{Conclusions}

All the schemes studied had a similar limited ability to predict the risk of stroke. With the exception of the original $\mathrm{CHADS}_{2}$, their performance is better than chance, though further development is required to improve the accuracy of the tools in older people and it might be better to pragmatically recommend that clinicians classify all patients over 75 as high risk and offer oral anticoagulation for these patients until better tools are available.

We are grateful to all the 260 MidReC BAFTA trial investigators listed in the original paper who recruited participants and to the patients who took part.

Contributors: RH, JM, GYHL, and DAF conceived the study. RDRH and AKR wrote the first draft, and the paper was edited by all authors. AKR did the statistical analysis. All authors interpreted the data, critically revised the draft, and gave approval for the paper to be published. $\mathrm{RDRH}$ is guarantor.

Funding: BAFTA was funded by the Medical Research Council, grant G9900264, with additional Service Support funding from the National Institute for Health Research (NIHR). The analyses in this paper were supported by Clinical Trial Unit core funding from the NIHR Health Technology Assessment and by the NIHR National School for Primary Care Research.

Competing interests: All authors have completed the Unified Competing Interest form at www.icmje.org/coi_disclosure.pdf (available on request from the corresponding author) and declare: no support from any organisation for the submitted work; GL has non-financial interests (author of the $\mathrm{CHADS}_{2}$-VASc score).

Ethical approval: Not required.

Data sharing: No additional data available.

1 Miyasaka Y, Barnes ME, Bailey KR, Cha SS, Gersh BJ, Seward JB, et al. Mortality trends in patients diagnosed with first atrial fibrillation-a 21-year community study. J Am Coll in patients diagnosed with

2 Fitzmaurice DA, Hobbs FDR, Jowett S, Mant J, Murray ET, Holder R, et al. Screening versus routine practice for detection of atrial fibrillation in people aged 65 or over: cluster randomised controlled trial. BMJ 2007;335:383-6.

3 Wolf PA, Abbott RD, Kannell WB. Atrial fibrillation as an independent risk factor for stroke: the Framingham study. Stroke 1991;22:983-8.

4 Aguilar MI, Hart R. Oral anticoagulants for preventing stroke in patients with non-valvular atrial fibrillation and no previous history of stroke or transient ischemic attacks. Cochrane Database Syst Rev 2005;3:CD001927.

$5 \quad$ Koudstaal PJ. Antiplatelet therapy for preventing stroke in patients with nonrheumatic atrial fibrillation and a history of stroke or transient ischemic attacks. Cochrane Database Syst Rev 1996;1:CD000186.

6 Van Walraven C, Hart RG, Singer DE, Laupacis A, Connolly S, Petersen P, et al. Oral anticoagulants vs aspirin in nonvalvular atrial fibrillation: an individual patient meta-analysis. JAMA 2002;288:2441-8.

7 Gage BF, Waterman AD, Shannon W, Boechler M, Rich MW, Radford MJ. Validation of clinical classification schemes for predicting stroke: results of the National Registry of Atrial Fibrillation. JAMA 2001:285:2864-70.

8 Van Walraven C, Hart RG, Wells GA, Petersen P, Koudstaal PJ, Gullov AL, et al. A clinical prediction rule to identify patients with atrial fibrillation and a low risk for stroke while taking aspirin. Arch Intern Med 2003;163:936-43.

9 Stroke Risk in Atrial Fibrillation Working Group. Comparison of 12 risk stratification schemes to predict stroke in patients with nonvalvular atrial fibrillation. Stroke 2008:39:1901-10.

10 Mant J, Wade DT, Winner S. Health care needs assessment: stroke. In: Stevens A, Raftery $\mathrm{J}$, Mant J, Simpson S, eds. Health care needs assessment: the epidemiologically based needs assessment reviews. 1st series. 2nd ed. Radcliffe Medical Press, 2004:141-244.

11 Mant J, Hobbs FDR, Fletcher K, Roalfe A, Fitzmaurice D, Lip GYH, et al. Warfarin versus aspirin for stroke prevention in an elderly community population with atrial fibrillation (the Birmingham Atrial Fibrillation Treatment of the Aged Study, BAFTA): a randomised controlled trial. Lancet 2007;370:493-503. 


\section{What is already known on this topic}

Atrial fibrillation is common and carries a major risk of stroke, particularly in older patients

Vitamin $\mathrm{K}$ antagonists, such as warfarin, reduce this risk by up to $65 \%$ but might be associated with risk of bleeding and require regular monitoring, but the main alternative to date, aspirin, is of marginal benefit

Guidelines recommend that clinicians use risk scores to classify patients into low, intermediate, and high risk of stroke to determine which patients should be offered warfarin

In routine practice, less than half of elderly patients deemed eligible for warfarin actually receive it

\section{What this study adds}

The main atrial fibrillation stroke risk scores advocated in international guidelines are of limited value in predicting subsequent risk of stroke from baseline in patients aged over 75

The predictive accuracy of the various stroke risk scores was similar, with a (low) C statistic of 0.55 to 0.62 Until better scores are available, clinicians might consider all patients over 75 as at high risk and offer formal anticoagulation rather than aspirin

12 Van Walraven C, Hart RG, Connolly S, Austin PC, Mant J, Hobbs FDR, et al. The influence of patient age on the effect of stroke prevention therapy in atrial fibrillation: a secondary analysis of data from randomized trials. Stroke 2009:40:1410-6.

13 Sato H, Ishikawa K, Kitabatake A, Ogawa S, Maruyama Y, Yokota Y, Japan Atrial Fibrillation Stroke Trial Group. Low-dose aspirin for prevention of stroke in low-risk patients with atrial fibrillation: Japan Atrial Fibrillation Stroke Trial. Stroke 2006;37:447-51

14 Wheeldon NM, Taylor DI, Anagnostou E, Cook D, Wales C, Oakley GDG. Screening for atrial fibrillation in primary care. Heart 1998;79:50-5.

15 Olesen JB, Lip GY, Hansen ML, Hansen PR, Tolstrup JS, Lindhardsen J, et al. Validation of risk stratification schemes for predicting stroke and thromboembolism in patients with atrial fibrillation: nationwide cohort study. BMJ 2011;342:d124.

16 Gage BF, Waterman AD, Shannon W, Boechler M, Rich MW, Radford MJ. Validation of clinical classification schemes for predicting stroke: results of the National Registry of Atrial Fibrillation. JAMA 2001;285:2864-70.

17 Wang TJ, Massaro JM, Levy D, Vasan RV, Wolf PA, D'Agostino RB, et al. A risk score for predicting stroke or death in individuals with new-onset atrial fibrillation in the community. The Framingham Study. JAMA 2003:290:1049-56.

18 National Institute for Health and Clinical Excellence. Atrial fibrillation: NICE guideline CG36. NICE, 2006:47.

19 Fuster V, Ryden LE, Cannom DS, Crijns HJ, Curtis AB, Ellenbogen KA, et al. ACC/AHA/ESC 2006 guidelines for the management of patients with atrial fibrillation-executive summary. Circulation 2006;114:e257-354.

20 Laupacis A, Albers G, Dalen J, Dunn MI, Jacobson AK, Singer DE. Antithrombotic therapy in atrial fibrillation. Chest 1998;114(suppl 5):579-89S.

21 Lip GYH, Nieuwlaat R, Pisters R, Lane DA, Crijns HJGM. Refining clinical risk stratification for predicting stroke and thromboembolism in atrial fibrillation using a novel risk factor approach: the Euro heart survey on atrial fibrillation. Chest 2010;137:263-72.

22 Rietbrock S, Heeley E, Plumb J, van Staa T. Chronic atrial fibrillation: incidence, prevalence, and prediction of stroke using the congestive heart failure, hypertension, age $>75$, diabetes mellitus, and prior stroke or transient ischemic attack $\left(\mathrm{CHADS}_{2}\right)$ risk stratification scheme. Am Heart J 2008;156:57-64.

23 Lip GYH, Lim HS. Atrial fibrillation and stroke prevention. Lancet Neurol 2007;6:981-93.

24 Gutierrez RG. Parametric frailty and shared frailty survival models. Stata J 2002;2:22-44

25 Schoenfeld D. Residuals for the proportional hazards regression model. Biometrika 1982;69:239-41.

26 Fang MC, Go AS, Chang Y, Borowsky L, Pomernacki NK, Singer DE, for the ATRIA Study Group. Comparison of risk stratification schemes to predict thromboembolism in people with nonvalvular atrial fibrillation. J Am Coll Cardiol 2008;51:810-5.

27 National Institute for Health and Clinical Excellence. Atrial fibrillation. The management of atrial fibrillation costing report. NICE, 2006.

28 Simpson CR, Wilson C, Hannaford PC, Williams D. Evidence for age and sex differences in the secondary prevention of stroke in Scottish Primary Care. Stroke 2005;36:1771-5.

29 Burton C, Isles C, Norrie J, Hanson R, Grubb E. The safety and adequacy of antithrombotic therapy for atrial fibrillation: a regional cohort study. Br J Gen Pract 2006;56:697-702.
30 Allen LaPointe NM, Governale L, Watkins J, Mulgund J, Anstrom KJ. Outpatient use of anticoagulants, rate-controlling drugs, and antiarrhythmic drugs for atrial fibrillation. $\mathrm{Am}$ Heart J 2007;154:893-8.

31 Laguna P, Martn A, del Arco C, Gargantilla P, Investigators in the Spanish Atrial Fibrillation in Emergency Medicine Study Group (GEFAUR). Risk factors for stroke and thromboprophylaxis in atrial fibrillation: what happens in daily clinical practice? The GEFAUR-1 study. Ann Emerg Med 2004;44:3-11.

32 Reynolds MR, Shah J, Essebag V, Olshansky B, Friedman PA, Hadjis T, et al. Patterns and predictors of warfarin use in patients with new-onset atrial fibrillation from the FRACTAL Registry. Am J Cardiol 2006:97:538-43.

33 Dubhghaill CT, Moonen L, O'Loughlin A, O'Keeffe S, Egan D, Murphy AW. Implementation of anticoagulation guidelines in general practice: a practice report. Ir Med $J$ 2003;96:296-9.

34 Pradhan AA, Levine MA. Warfarin use in atrial fibrillation: a random sample survey of family physician beliefs and preferences. Can J Clin Pharmacol 2002;9:199-202.

35 Rutten FH, Hak E, Stalman WA, Verheij TJ, Hoes AW. Is treatment of atrial fibrillation in primary care based on thromboembolic risk assessment? Fam Pract 2003:20:16-21.

36 Savage M, Teeling M, Bennett K, Feely J. Adherence to clinical guidance in the prescribing of oral antithrombotic medication in patients with atrial fibrillation. Ir J Med Sci 2006;175:46-9.

37 Partington SL, Abid S, Teo K, Oczkowski W, O'Donnell MJ. Pre-admission warfarin use in patients with acute ischemic stroke and atrial fibrillation: the appropriate use and barriers to oral anticoagulant therapy. Thromb Res 2007;120:663-9.

38 Lip GYH, Golding DJ, Nazir M, Beevers DG, Child DL, Fletcher RI. A survey of atrial fibrillation in general practice: the West Birmingham Atrial Fibrillation Project. $\mathrm{Br} J$ Gen Pract 1997;47:285-9.

39 Gudmundsdottir IJ, Helgason KO, Sigurdsson EL, Arnar DO. Use of warfarin anticoagulation in patients with atrial fibrillation in Iceland. Laeknabladid 2002;88:299-303.

40 Friberg L, Hammar N, Ringh M, Pettersson H, Rosenqvist M. Stroke prophylaxis in atria fibrillation: who gets it and who does not? Report from the Stockholm Cohort-study on Atrial Fibrillation (SCAF-study). Eur Heart $J$ 2006;27:1954-64.

41 Brophy MT, Snyder KE, Gaehde S, Ives C, Gagnon D, Fiore LD. Anticoagulant use for atrial fibrillation in the elderly. J Am Geriatr Soc 2004;52:1151-6.

42 Connolly S, Ezekowitz MD, Yusuf S, Eikelboom J, Oldgren J, Parekh A, et al. Dabigatran versus warfarin in patients with atrial fibrillation. $N$ Engl $J$ Med 2010:361:1139-51.

43 Gensch C, Hoppe U, Böhm M, Laufs U. Late-breaking clinical trials presented at the American Heart Association Congress in Chicago 2010. Clin Res Cardiol 2011:100:1-9.

44 Connolly SJ, Eikelboom J, Joyner C, Diener H-C, Hart R, Golitsyn S, et al. Axipiban in patients with atrial fibrillation. N Engl J Med 2011;364:806-17.

Accepted: 24 May 2011

Cite this as: $B M J 2011 ; 342: \mathrm{d} 3653$ 


\section{Tables}

\section{Table 1| Stroke risk stratification schemes for patients with atrial fibrillation}

\begin{tabular}{|c|c|c|c|}
\hline Risk scheme & Low risk & Moderate risk & High risk \\
\hline $\operatorname{CHADS}_{2}(2001)^{16 *}$ & Score 0 (original); 0 (revised) & Score 1-2 (original); 1 (revised) & Score 3-6 (original); 2-6 (revised) \\
\hline Framingham $(2003)^{17} \dagger$ & Score $0-7$ & Score $8-13$ & Score 14-31 \\
\hline NICE guidelines $(2006)^{18}$ & $\begin{array}{l}\text { Age }<65 \text { with no history of } \\
\text { embolism, hypertension, } \\
\text { diabetes, or other clinical risk } \\
\text { factors }\end{array}$ & $\begin{array}{l}\text { Age } \geq 65 \text { with no high risk factors; age }<75 \\
\text { with hypertension, diabetes, or vascular } \\
\text { disease }\end{array}$ & $\begin{array}{l}\text { Previous ischaemic stroke, transient ischaemic } \\
\text { attack, or systemic embolic event; age } \geq 75 \text { with } \\
\text { hypertension, diabetes, or vascular disease; clinical } \\
\text { evidence of valve disease or heart failure; impaired } \\
\text { left ventricular function on echocardiography }\end{array}$ \\
\hline $\begin{array}{l}\text { ACC/AHA/ESC guidelines } \\
(2006)^{19}\end{array}$ & No risk factors & $\begin{array}{l}\text { Patient with only one risk factor: age } \geq 75 \text {; } \\
\text { hypertension, diabetes, heart failure, or } \\
\text { impaired left ventricular function }\end{array}$ & $\begin{array}{l}\text { Previous stroke, transient ischaemic attack, } \\
\text { systemic embolism; mitral stenosis; prosthetic heart } \\
\text { valve; two or more of: age } \geq 75 \text {, hypertension, } \\
\text { diabetes, heart failure, or impaired left ventricular } \\
\text { function }\end{array}$ \\
\hline ACCP guidelines $(2008)^{20}$ & Age $\leq 75$ with no risk factors & $\begin{array}{l}\text { Patients with only one risk factor: age }>75 \text {, } \\
\text { hypertension, diabetes, or impaired left } \\
\text { ventricular function with or without heart } \\
\text { failure }\end{array}$ & $\begin{array}{l}\text { Previous stroke, transient ischaemic attack, } \\
\text { systemic embolism; two or more of: age }>75 \text {, } \\
\text { hypertension, diabetes, or impaired left ventricular } \\
\text { function with or without heart failure }\end{array}$ \\
\hline Rietbrock modified $(2008)^{22} \ddagger$ & NA & NA & NA \\
\hline $\mathrm{CHA}_{2} \mathrm{DS}_{2}-\mathrm{VASc}(2009)^{21} \S$ & Score 0 & Score 1 & Score 2-9 \\
\hline
\end{tabular}

$\mathrm{NA}=$ not available.

*Scoring system based on previous stroke or transient ischaemic attack ( 2 points), age $\geq 75$ ( 1 point), hypertension ( 1 point), diabetes ( 1 point), congestive heart failure (1 point).

†Scoring system based on age (max 10 points), female ( 6 points), raised systolic blood pressure (max 4 points), diabetes (5 points), previous stroke or transient ischaemic attack (6 points).

¥Scoring system based on age (max 6 points), female (1 point), diabetes (1 point), history of stroke/transient ischaemic attack (6 points).

$\S$ Scoring system based on congestive heart failure ( 1 point), hypertension ( 1 point), age $\geq 75$ ( 2 points), diabetes ( 1 point), stroke/transient ischaemic attack/thromboembolism (2 points), vascular disease (1 point), age 65-74 (1 point), female (1 point). 
Table 2/ Characteristics of participants in Birmingham Atrial Fibrillation in the Aged (BAFTA) trial who were not taking warfarin

\begin{tabular}{lc} 
Risk factor & No (\%) \\
Age (years): & $253(38)$ \\
\hline $75-79$ & $266(40)$ \\
\hline $80-84$ & $146(22)$ \\
\hline$\geq 85$ & $367(55)$ \\
\hline Men & \\
\hline Systolic BP (mm Hg): & $83(13)$ \\
\hline$<120$ & $208(31)$ \\
\hline $120-139$ & $239(36)$ \\
\hline $140-159$ & $124(19)$ \\
\hline $160-179$ & $11(2)$ \\
\hline$\geq 180$ & $91(14)$ \\
\hline Diabetes & $355(53)$ \\
\hline Hypertension & $78(12)$ \\
\hline Previous stroke or transient ischaemic attack & $42(6)$ \\
\hline Valve disease & $74(11)$ \\
\hline Myocardial infarction & $108(16)$ \\
\hline Angina & $121(18)$ \\
\hline Heart failure & \\
\hline &
\end{tabular}


Table 3| Distribution and risk of ischaemic stroke in patients aged $\geq 75$ with atrial fibrillation who were not taking warfarin, by classification of risk and scheme*

\begin{tabular}{|c|c|c|c|}
\hline Risk & Distribution (\%) & Events/person years & Risk/100 person years $(95 \% \mathrm{Cl}+)$ \\
\hline \multicolumn{4}{|c|}{ CHADS $_{2}$ original } \\
\hline Low risk & 0 & - & - \\
\hline Moderate risk & 73 & $34 / 1113$ & 3.05 (2.12 to 4.27$)$ \\
\hline High risk & 27 & $20 / 402$ & 4.98 (3.07 to 7.58 ) \\
\hline \multicolumn{4}{|c|}{ CHADS $_{2}$ revised } \\
\hline Low risk & 0 & - & - \\
\hline Moderate risk & 31 & $7 / 505$ & $1.39(0.56$ to 2.86$)$ \\
\hline High risk & 69 & $47 / 1010$ & 4.65 (3.42 to 6.19$)$ \\
\hline \multicolumn{4}{|l|}{ Framingham } \\
\hline Low risk & 17 & $2 / 263$ & 0.76 (0.09 to 2.72$)$ \\
\hline Moderate risk & 42 & $24 / 625$ & 3.84 (2.48 to 5.66$)$ \\
\hline High risk & 41 & $28 / 627$ & 4.47 (2.97 to 6.39$)$ \\
\hline \multicolumn{4}{|l|}{ NICE } \\
\hline Low risk & 0 & - & - \\
\hline Moderate risk & 25 & $6 / 415$ & 1.45 (0.53 to 3.12$)$ \\
\hline High risk & 75 & $48 / 1100$ & 4.36 (3.23 to 5.74$)$ \\
\hline \multicolumn{4}{|c|}{ ACC/AHA/ESC $\neq$} \\
\hline Low risk & 0 & - & - \\
\hline Moderate risk & 31 & $7 / 505$ & 1.39 (0.56 to 2.86$)$ \\
\hline High risk & 69 & $47 / 1010$ & 4.65 (3.42 to 6.19$)$ \\
\hline \multicolumn{4}{|l|}{ ACCP } \\
\hline Low risk & 3 & $1 / 42$ & 2.38 (0.06 to 13.27$)$ \\
\hline Moderate risk & 32 & 9/519 & 1.73 (0.79 to 3.29 ) \\
\hline High risk & 65 & $44 / 954$ & 4.61 (3.35 to 6.19$)$ \\
\hline
\end{tabular}

*With $\mathrm{CHA}_{2} \mathrm{DS}_{2}-\mathrm{VASc}$, all patients would be classified as "high risk."

†Calculated with Poisson exact method.

‡Equal to $\mathrm{CHADS}_{2}$ revised because of unavailability of risk factors (left ventricular function, mitral stenosis, and prosthetic heart valve) in BAFTA data. 
Table 4| Risk of ischaemic stroke in patients aged $\geq 75$ with atrial fibrillation who were not taking warfarin, by incremental score in risk schemes

Score Events/person years Risk/100 person years $(95 \% \mathrm{Cl})$

CHADS $_{2}$ index

\begin{tabular}{|c|c|c|}
\hline 0 & - & - \\
\hline 1 & $7 / 505$ & 1.39 (0.56 to 2.86$)$ \\
\hline 2 & $27 / 607$ & 4.45 (2.95 to 6.41$)$ \\
\hline 3 & $13 / 248$ & 5.24 (2.82 to 8.80$)$ \\
\hline 4 & $4 / 115$ & 3.48 (0.96 to 8.67$)$ \\
\hline 5 & $3 / 36$ & 8.57 (1.80 to 23.06$)$ \\
\hline 6 & $0 / 2$ & $0(0 \text { to } 84.19)^{*}$ \\
\hline \multicolumn{3}{|c|}{$\mathrm{CHA}_{2} \mathrm{DS}_{2}$-VASc } \\
\hline 0 & - & - \\
\hline 1 & - & - \\
\hline 2 & $6 / 284$ & $2.11(0.77$ to 4.60$)$ \\
\hline 3 & $10 / 529$ & 1.89 (0.91 to 3.48$)$ \\
\hline 4 & $24 / 359$ & 6.69 (4.28 to 9.95$)$ \\
\hline 5 & $8 / 197$ & $4.06(1.75$ to 8.01$)$ \\
\hline 6 & $6 / 110$ & 5.45 (2.00 to 11.87$)$ \\
\hline 7 & $0 / 31$ & $0(0 \text { to } 11.90)^{*}$ \\
\hline 8 & $0 / 5$ & $0(0 \text { to } 73.78)^{*}$ \\
\hline \multicolumn{3}{|c|}{ 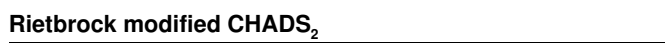 } \\
\hline 0 & - & 一 \\
\hline 1 & - & - \\
\hline 2 & - & - \\
\hline 3 & - & - \\
\hline 4 & $3 / 258$ & $1.16(0.24$ to 3.40$)$ \\
\hline 5 & $14 / 492$ & 2.84 (1.56 to 4.77$)$ \\
\hline 6 & $13 / 391$ & $3.32(1.77$ to 5.69$)$ \\
\hline 7 & $8 / 189$ & $4.23(1.83$ to 8.34$)$ \\
\hline 8 & $3 / 12$ & $25.0(5.16$ to 73.06$)$ \\
\hline 9 & 0 & - \\
\hline 10 & $4 / 27$ & 14.81 (4.04 to 37.93$)$ \\
\hline 11 & $5 / 66$ & 7.58 (2.46 to 17.68$)$ \\
\hline 12 & $3 / 46$ & $6.52(1.34$ to 19.06$)$ \\
\hline 13 & $1 / 34$ & $2.94(0.07$ to 16.39$)$ \\
\hline
\end{tabular}

*One sided $97.5 \%$ confidence interval. 
Table 5| Performance of risk stratification schemes to predict ischaemic stroke in patients aged $\geq 75$ with atrial fibrillation who were not taking warfarin

\begin{tabular}{|c|c|c|c|}
\hline Risk scheme & C statistic ${ }^{*}$ & Hazard ratio $(95 \% \mathrm{Cl})$ & $P$ value \\
\hline \multicolumn{4}{|l|}{ Stratum } \\
\hline $\mathrm{CHADS}_{2}$ original & $0.55(0.49$ to 0.61$)$ & $1.61(0.93$ to 2.80$)$ & 0.09 \\
\hline $\mathrm{CHADS}_{2}$ revised & 0.61 (0.57 to 0.66$)$ & 3.29 (1.49 to 7.28$)$ & 0.003 \\
\hline \multicolumn{4}{|l|}{ Framingham: } \\
\hline Moderate $v$ low & 0.59 (0.55 to 0.65$)$ & $4.99(1.18$ to 21.10$)$ & 0.03 \\
\hline High $v$ moderate & & 1.17 (0.68 to 2.03$)$ & 0.56 \\
\hline NICE & 0.59 (0.54 to 0.63$)$ & 2.93 (1.25 to 6.68$)$ & 0.01 \\
\hline ACC/AHA/ESC $\dagger$ & 0.61 (0.57 to 0.66$)$ & 3.29 (1.49 to 7.28$)$ & 0.003 \\
\hline \multicolumn{4}{|l|}{ ACCP: } \\
\hline Moderate $v$ low & $0.60(0.54$ to 0.65$)$ & 0.75 (0.09 to 5.89$)$ & 0.78 \\
\hline$\underline{\text { High } v \text { moderate }}$ & & 2.61 (1.27 to 5.35$)$ & 0.009 \\
\hline \multicolumn{4}{|l|}{ Scores } \\
\hline $\mathrm{CHADS}_{2}$ index & $0.61(0.54$ to 0.68$)$ & 1.35 (1.07 to 1.70$) \ddagger$ & 0.01 \\
\hline$\underline{\text { Rietbrock modified }}$ & $0.62(0.59$ to 0.68$)$ & 1.17 (1.06 to 1.29$) \ddagger$ & 0.001 \\
\hline $\mathrm{CHA}_{2} \mathrm{DS}_{2}-\mathrm{VASc}$ & $0.60(0.55$ to 0.68$)$ & 1.21 (0.99 to 1.47$) \ddagger$ & 0.06 \\
\hline
\end{tabular}

*Assesses discrimination where 0.5 is non-informative test.

†Equal to $\mathrm{CHADS}_{2}$ revised because of unavailability of risk factors left ventricular function, mitral stenosis, and prosthetic heart valve in BAFTA data. $\ddagger$ Per unit increase in score. 
Table 6 | Cox proportional hazards model estimating risk of ischaemic stroke in people aged $\geq 75$ with atrial fibrillation who were not taking warfarin

\begin{tabular}{lcc} 
Variable & Hazard ratio & P value \\
Age (per 5 years) & $1.26(0.93$ to 1.72$)$ & 0.14 \\
\hline Sex & $0.99(0.57$ to 1.70$)$ & 0.96 \\
\hline Systolic blood pressure $($ per $5 \mathrm{~mm} \mathrm{Hg})$ & $1.01(0.94$ to 1.08$)$ & 0.86 \\
\hline Hypertension & $1.10(0.62$ to 1.95$)$ & 0.74 \\
\hline Diabetes & $2.06(1.07$ to 3.98$)$ & 0.03 \\
\hline Heart failure & $0.78(0.36$ to 1.68$)$ & 0.53 \\
\hline Myocardial infarction & $0.52(0.18$ to 1.50$)$ & 0.22 \\
\hline Angina & $1.12(0.30$ to 2.44$)$ & 0.79 \\
\hline Valve disease & $0.96(0.58$ to 3.13$)$ & 0.95 \\
\hline Stroke/TIA & $2.59(1.36$ to 4.90$)$ & 0.003 \\
\hline TIA=transient ischaemic attack. & & \\
\hline
\end{tabular}




\section{Figure}

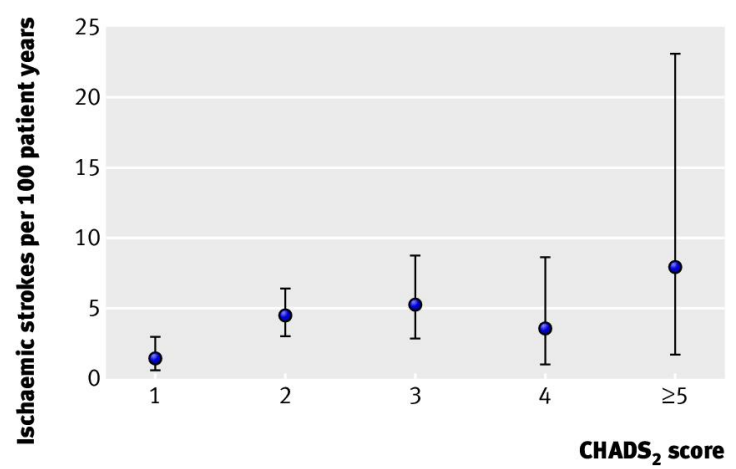

Risk of ischaemic stroke (point estimates with $95 \%$ confidence interval) by individual CHADS $_{2}$ score 